See discussions, stats, and author profiles for this publication at: https://www.researchgate.net/publication/267335692

\title{
Applicability of MEP and SEMEP for computing total sediment load (Case Study: Chelichay Catchment in Golestan Province)
}

Article in KSCE Journal of Civil Engineering · June 2014

DOI: 10.1007/s12205-014-1454-6

\section{CITATION}

1

4 authors:

Amir A. Dehghani

1. Gorgan University of Agricultural Sciences and Natural Resources 55 PUBLICATIONS 350 CITATIONS

SEE PROFILE

Mohammad Hossein Omid

University of Tehran

79 PUBLICATIONS 447 CITATIONS

SEE PROFILE
READS

109

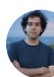

Arman Haddadchi

Griffith University

18 PUBLICATIONS 194 CITATIONS

SEE PROFILE

Neshat Movahedi

Gorgan University of Agricultural Sciences and Natural Resources

8 PUBlications 11 Citations

SEE PROFILE

Some of the authors of this publication are also working on these related projects:

Project transitions in open channel View project

Project Effect of sorption process on pollutant transport View project 


\title{
Applicability of MEP and SEMEP for Computing Total Sediment Load (Case Study: Chelichay Catchment in Golestan Province)
}

\author{
Amir A. Dehghani*, Arman Haddadchi**, Mohammad H. Omid***, and Neshat Movahedi****
}

Received July 28, 2013/Revised October 25, 2013/Accepted November 5, 2013/Published Online June 20, 2014

\begin{abstract}
A reliable and consistent method of computing total sediment discharge within a river system is one of the most important practical objectives of research in fluvial processes. Modified Einstein Procedure (MEP) and Series Expansion Modified Einstein Procedure (SEMEP) methods were used to determine total sediment load on the basis of the data collected from a depth-integrated sediment. On the basis of Fifty nine data sets measured from 5 rivers including a sand bed river and four garvel bed rivers, the accuracy of sediment discharge calculations were examined. In a sand bed river the results of SEMEP method was remarkably better than MEP method. In SEMEP method, calculated and measured total load are almost equal (Mean discrepancy ratio is 1.27) while MEP model compute total load discharge approximately 3 times greater than averaged measured values (Mean discrepancy ratio is 2.9). In all gravel bed rivers, except one, SEMEP method was better in predicting total load than MEP method. The results show that SEMEP method is more comprehensive in computing total sediment load from informations gathered with depth integrated suspended load sampler in both gravel and sand bed rivers.
\end{abstract}

Keywords: sediment, total load, einstein, MEP, SEMEP

\section{Introduction}

Alluvial channels must be designed to carry definite water and sediment discharges. The rate of total load transport must be treated as a variable affecting the design of the channel. Similarly, a knowledge of the total sediment transport rate is required for estimating the rate of settling in reservoirs. A knowledge of the total load transport is required to assess aggradation and degradation and river-training problems for their solution (Garde et al., 2000).

Julien (2010) divided total sediment load into three different ways: i) by the type of movement; the total sediment load can be divided into the bedload and the suspended load; ii) by the method of measurement; the total sediment load consists of the measured load and the unmeasured load, the measured sediment load is only part of the suspended load, while the unmeasured sediment load consists of the entire bedload plus the fraction of the suspended load, transported below the lowest sampling elevation; iii) by the source of sediment; the total sediment load is equal to the fine sediment fraction coming from upstream, also called washload plus the coarser grain sizes from the bed material load. The $10^{\text {th }}$ percentile of the bed material $\left(\mathrm{d}_{10}\right)$ is commonly used as the breakpoint between washload $\left(\mathrm{d}_{\mathrm{s}}<\mathrm{d}_{10}\right)$ and bed material load $\left(\mathrm{d}_{\mathrm{s}}>\mathrm{d}_{10}\right)$.

Numerous sediment transport formulas have been proposed in the past decades and subsequent modifications of original formulations have been prescribed. Although significant progress has been made, none of the existing sediment transport formulas can determine the total load. In engineering practice, several formulas are compared with field observations to select the most appropriate equation at a given field site (Haddadchi et al., 2012). For given streamflow conditions, any sediment transport equation can only predict the sediment transport capacity of a given bed sediment mixture.

Einstein (1950) developed a method to calculate total load, based on evaluating the bed load transport and integrating the suspended sediment discharge equation (Shah-Fairbank, 2009). Einstein bed load transport approach is based on the assumption that in steady uniform flow and equilibrium between the number of particles eroded and deposited per unit area and time. The method of suspended load transport of Einstein is based on parabolic distribution of the fluid mixing coefficient and a logarithmic distribution of the velocity.

Investigation on shallow alluvial streams in US indicated that Einstein's method gives results which are far from the observed

*Associate Professor, Dept. of Water Engineering, Gorgan University of Agricultural Sciences and Natural Resources, Gorgan, Iran (Corresponding Author, E-mail: a.dehghani@gau.ac.ir)

**Ph.D. Candidate, Australian Rivers Institute, Griffith University, Nathan QLD 4111, Australia (E-mail: arman.haddadchi@griffithuni.edu.au)

***Professor, Dept. of Irrigation and Reclamation Engineering, University of Tehran, Karaj, Iran (Email: momid@ut.ac.ir)

****MS.c Graduated, Dept. of Water Engineering, Gorgan University of Agricultural Sciences and Natural Resources, Gorgan, Iran (E-mail: neshat.movahedi@gmail.com) 
values. For this reason, Colby and Hembree (1955) and Schroeder (1956) developed a procedure called Modified Einstein Procedure (MEP) for determination of total load of such streams (Garde et al., 2000). This method was developed to provide the total sediment discharge at a given point in time for a given crosssection. In this method, the total sediment discharge is determined by measuring a portion of the suspended sediment discharge (depth integrated sampler) and extrapolating to estimate the unmeasured sediment discharge (in the zone located very near the bed).

Colby and Hembree (1955) and Colby and Hubbell (1967) developed a modified version of Einstein's Procedure (MEP) that used data from a single cross section to calculate the total sediment discharge for a specific stream reach. The MEP is considered an improvement over the original Einstein method because it is simpler in computation and uses characteristics more readily available from actual stream measurements. However, Lara (1966) noticed that the approach for calculation of Rouse number determined by Colby and Hembree was subjective and could result in many different answers based on the bins (particle size classes) used. Therefore, Lara introduced a least squares regression to determine the Rouse number.

The major differences between Einstein's original (1950) procedure and the modified Einstein procedure (Colby and Hembree, 1955) are as follows: a) The modified procedure is based on the measured mean velocity rather than on the calculated velocity from the given slope, and the depth is observed in each vertical at which the velocity is measured; $b$ ) The suspended load exponent $Z$ (Rouse number) is determined from the observed $Z$ value for a dominant grain size; c) A slight change in the hiding factor that depends on representative grain size and logarithmic velocity distribution is introduced; d) the water depth is used to replace the hydraulic radius; e) The value of Einstein intensity of bed-load transport is arbitrarily divided by a factor of two to fit the observed transport data more closely (Yang, 1996).

In the past 20 years, programs have been developed to aid engineers in calculating total sediment discharge based on MEP, and Several re-modifications have been proposed that aid in the total load calculation based on the MEP; Shen and Hung (1983) developed the Remodified Einstein Procedure to determine an even more accurate calculation of total sediment transport rates from the flow and suspended sediment measurement based on MEP. Blanchard et al. (2011) used the Modified Einstein Procedure (MEP) to determine bedload instead of collecting bedload samples for future investigations. They concluded that the MEP model overestimated bedload discharge by a relatively large amount for every comparison.

Shah-Fairbank et al. (2008) determined modes of transport by analyzing the ratio of shear velocity $\left(u_{*}\right)$ to settling velocity $(\omega)$ as a function of ratio of suspended sediment load to total load $\left(q_{s}\right)$ $q_{t}$ ) and the relative submergence $\left(h / d_{s}\right)$. They concluded that when the value of $u_{*} / \omega$ is greater than 5, MEP is applicable; however, when the value of $u_{*} / \omega$ is between 1 and 5 both the
Einstein Procedure and MEP must be verified. There are however some disadvantages to the MEP. Since, the MEP involves the extrapolation of measured suspended sediment discharge and computed bed load discharge (Albert, 2004).

The most recent development of the MEP is based on the series expansion of the Einstein integrals determined by Guo and Julien (2004). Their solution for computing the Einstein Integrals is both accurate and rapid compared to the trapezoidal rule (utilized on MEP method). The Series Expansion of the Modified Einstein Procedure (SEMEP) removes the empiricism found in a traditional MEP by performing calculation based on a median particle size in suspension and calculating bed load directly from the measured load (Shah-Fairbank et al., 2011).

SEMEP contains four main modifications to MEP: a) SEMEP solves the Einstein integrals quickly and accurately based on a series expansion; b) Instead of dividing the suspended sediment and bed material samples into particle size classes, the total sediment discharge calculation is based on a median grain size in suspension $\left(d_{50 \text { ss }}\right)$; c) For depth-integrated samples the Rouse number $(R o)$ is determined directly by calculating the fall velocity $(\omega)$ based on $d_{50 s s}$, the shear velocity $\left(u_{*}=\sqrt{g h s}\right)$ and assuming the value of the von Karman constant $(\kappa)$ is 0.4 ; d) SEMEP uses the measured unit sediment discharge and Rouse number to determine the unit bed load discharge directly (ShahFairbank, 2009).

Although a number of case studies available to predict bed load and suspended load based on formulas and intelligent methods (e.g., Gomez et al., 1989; Habersack et al., 2002; Haddadchi et al., 2013a; Altunkaynak 2010; Haddadchi et al. 2013b; ZHU et al., 2007; Azamathulla et al., 2009; Azamathulla et al., 2012), but there are limited studies on evaluating total loads (Yang et al., 2009; Haddadchi et al., 2013c).

In this study, total sediment discharge were calculated by using Modified Einstein Procedure (MEP) and the Series Expansion of the Modified Einstein Procedure (SEMEP) based on measured total load in five rivers with different morphologic aspects and different bed material types (gravel-bed and sand-bed).

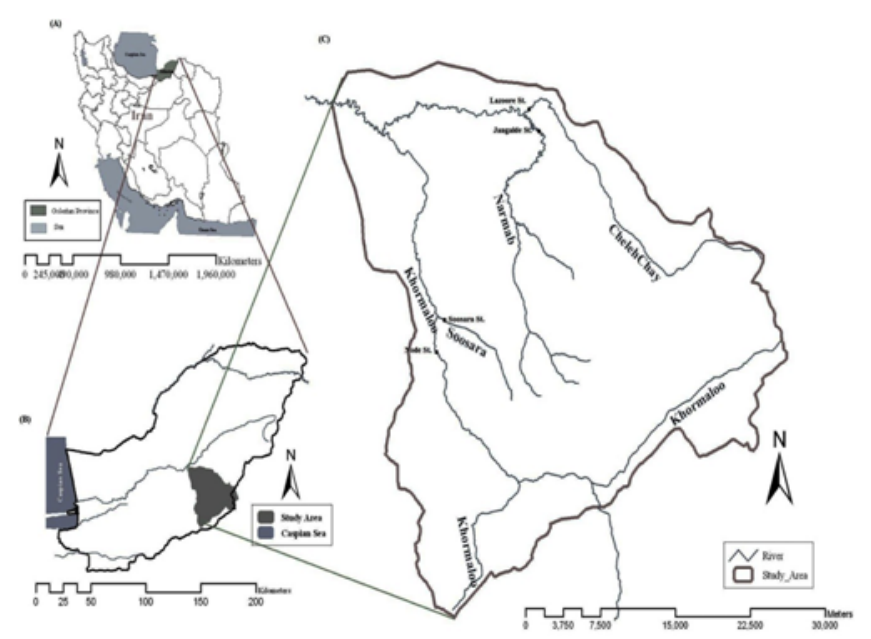

Fig. 1. The Study Area (Chelichay Catchment and Rivers) 


\section{Material and Methods}

\subsection{Study Area}

This study was conducted in Chelichay catchment (37 13' N; $5524^{\prime}$ E), located in north eastern of Iran (see Fig. 1). Fifty nine

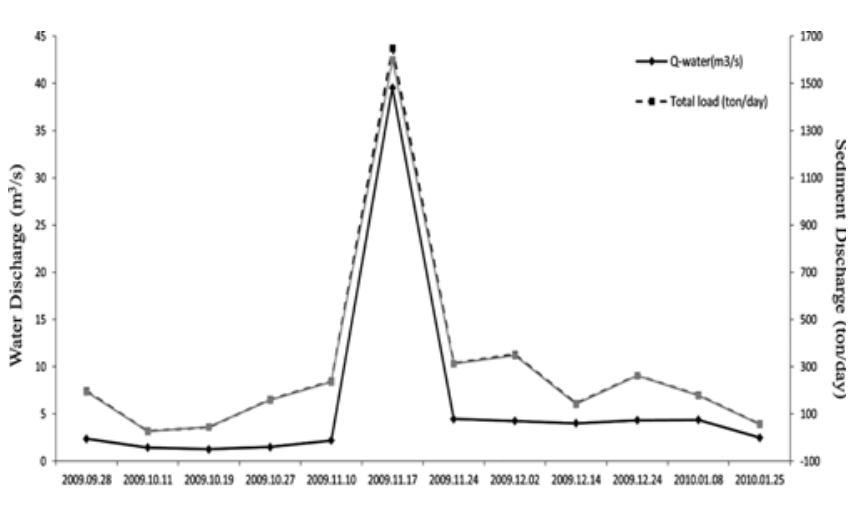

Date

Fig. 2. The Variation of Flow Discharge $\left(\mathrm{m}^{3} / \mathrm{s}\right)$, Total Sediment Load (ton/day) and Suspended Load (ton/day) Over Different Dates of Sampling in Qaresoo River data sets are utilized for analysing all five rivers in Chelichay catchment, including a sand bed river (Qaresoo River, $\mathrm{n}=12$ data sets), and garvel bed rivers (Narmab River, $\mathrm{n}=9$; Chehelchay River, $\mathrm{n}=15$; Khormaloo River, $\mathrm{n}=15$ and Soosara River, $\mathrm{n}=$ 9). Samplings are carried out in different dates 2009-2010 for different rivers (Figs. 2 and 3).

\subsection{SEMEP formulation}

The sediment flux by advection can be described by the product of sediment concentration $\mathrm{C}$ and flow velocity $\mathrm{v}$. The total unit sediment discharge is calculated by adding the bed and suspended sediment discharges per unit width, as follows (Julien 2010):

$$
q_{t}=q_{b}+\int^{h} C v d z
$$

where $\quad q_{b}=$ Unit bed sediment discharge

$$
q_{t}=\text { Unit total sediment discharge }
$$

Einstein (1950) suggested the following relationship between the unit bed sediment discharge and reference concentration

$$
C_{z b}=\frac{q_{b}}{v_{z b} z_{b}}=\frac{q_{b}}{11.6 u_{*} z_{b}}
$$
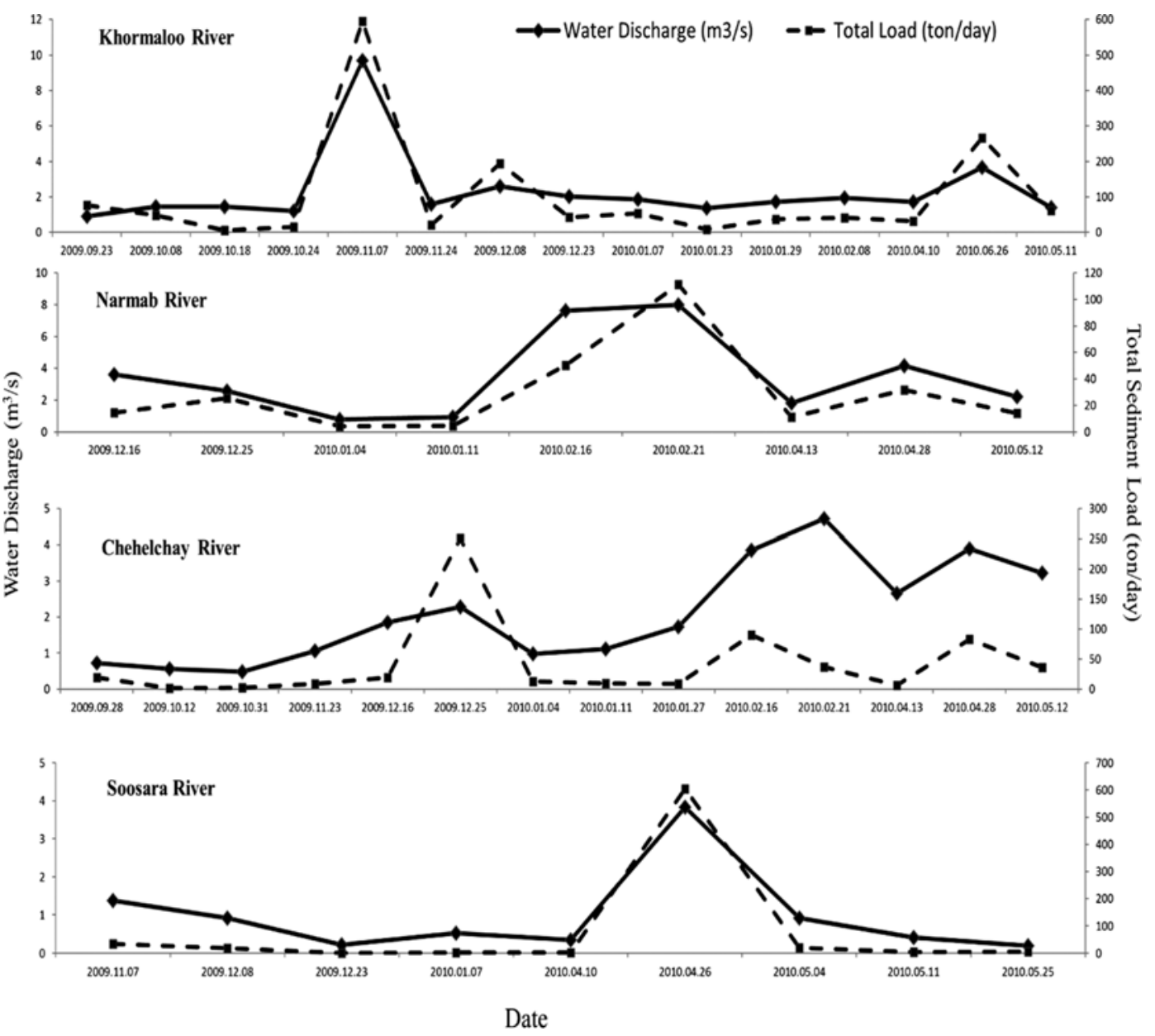

Fig. 3. The Variation of Flow Discharge $\left(\mathrm{m}^{3} / \mathrm{s}\right)$ and Total Sediment Load (ton/day) in Gravel Bed Rivers (Khormaloo, Narmab, Chehelchay and Soosara) in All Sampling Dates 
where $v_{z b}=$ Reference velocity in the bed layer.

By assuming a logarithmic distribution for turbulent velocity profile and estimation of concentration profile from Rouse equation the following relation can be obtained:

$$
\begin{aligned}
& q_{t}=q_{b}+0219 q_{b} \frac{B^{R o-1}}{(1-B)^{R o}}\left\{\ln \left(\frac{30 h}{d_{s}}\right) J_{1 S}+J_{2 S}\right\} \\
& J_{1 s}=\int_{B}^{1}\left(\frac{1-z^{*}}{z^{*}}\right)^{R o} d z^{*} \\
& J_{2 S}=\int_{B}^{1} \ln z^{*}\left(\frac{1-z^{*}}{z^{*}}\right)^{R o} d z^{*}
\end{aligned}
$$

Where $B=2 d_{s} / h, z^{*}=z / h, R_{o}=$ Rouse number $=\omega / \beta_{\mathrm{s}} \kappa u_{*}$, and $J_{1 \mathrm{~S}}$ and $J_{2 \mathrm{~S}}$ are known as the Einstein integrals and are evaluated within the suspended sediment zone. The SEMEP formulation uses depth-integrated suspended sediment samples, which assume $\kappa=0.4, z_{b}=2 d_{s}=2 d_{65}$ of the bed material, $b_{s}$ is momentum correction factor, assumed to Eq. (1), and $\omega$ is based on the median grain diameter of the measured suspended sediment $\left(\mathrm{d}_{50 \text { ss }}\right)$. The values of $J_{1 \mathrm{~S}}$ and $J_{2 \mathrm{~S}}$ are also determined by using the series expansion given by Guo and Julien (2004).

\subsection{Field Data Measurements}

Two depth integrating suspended load samplers (DH-48 and D-49), and two bed load samplers (Helley-Smith and BLSH) were used to measure total load discharge. The DH-48 is a lightweight sampler $(2 \mathrm{Kg})$ for collection of suspended-sediment samples where wading rod sampler suspension is used. The D49 weighs $28 \mathrm{Kg}$ in which with cable suspension is designed for use in streams beyond the range of hand-operated equipment. Bed load measurements were performed with two types of 3inch Helley-Smith sampler. Original Helley-Smith sampler weighs $50 \mathrm{Kg}$ deployed from a cableway about $6 \mathrm{~m}$ above the water level. This sampler is used for water depth more than $1 \mathrm{~m}$. Another sampler is BLSH bed load sampler which is a handheld

Table 1. Summary of Geometical and Hydraulical Specifications in Rivers

\begin{tabular}{c|c|c|c|c|c}
\hline Rivers & Qaresoo & Narmab & ChehelChay & Khormaloo & Soosara \\
\hline Data utilized & 12 & 9 & 15 & 14 & 9 \\
\hline Bed Slope (\%) & 0.14 & 0.03 & 1.75 & 1.09 & 0.17 \\
\hline Velocity $\left(\mathrm{ms}^{-1}\right)$ & $0.32-0.89$ & $0.28-1.32$ & $0.4-1.14$ & $0.7-1.4$ & $0.21-1$ \\
\hline Hydraulic Radius (m) & $0.45-2.4$ & $0.16-0.53$ & $0.15-0.32$ & $0.21-0.34$ & $0.08-0.46$ \\
\hline Width (m) & $15.5-18$ & $7-19$ & $8.5-21$ & $12-26$ & $4-8$ \\
\hline $\mathrm{h}_{\text {ave }}(\mathrm{m})$ & 3.28 & 1.19 & 0.9 & 0.94 & 1.07 \\
\hline
\end{tabular}

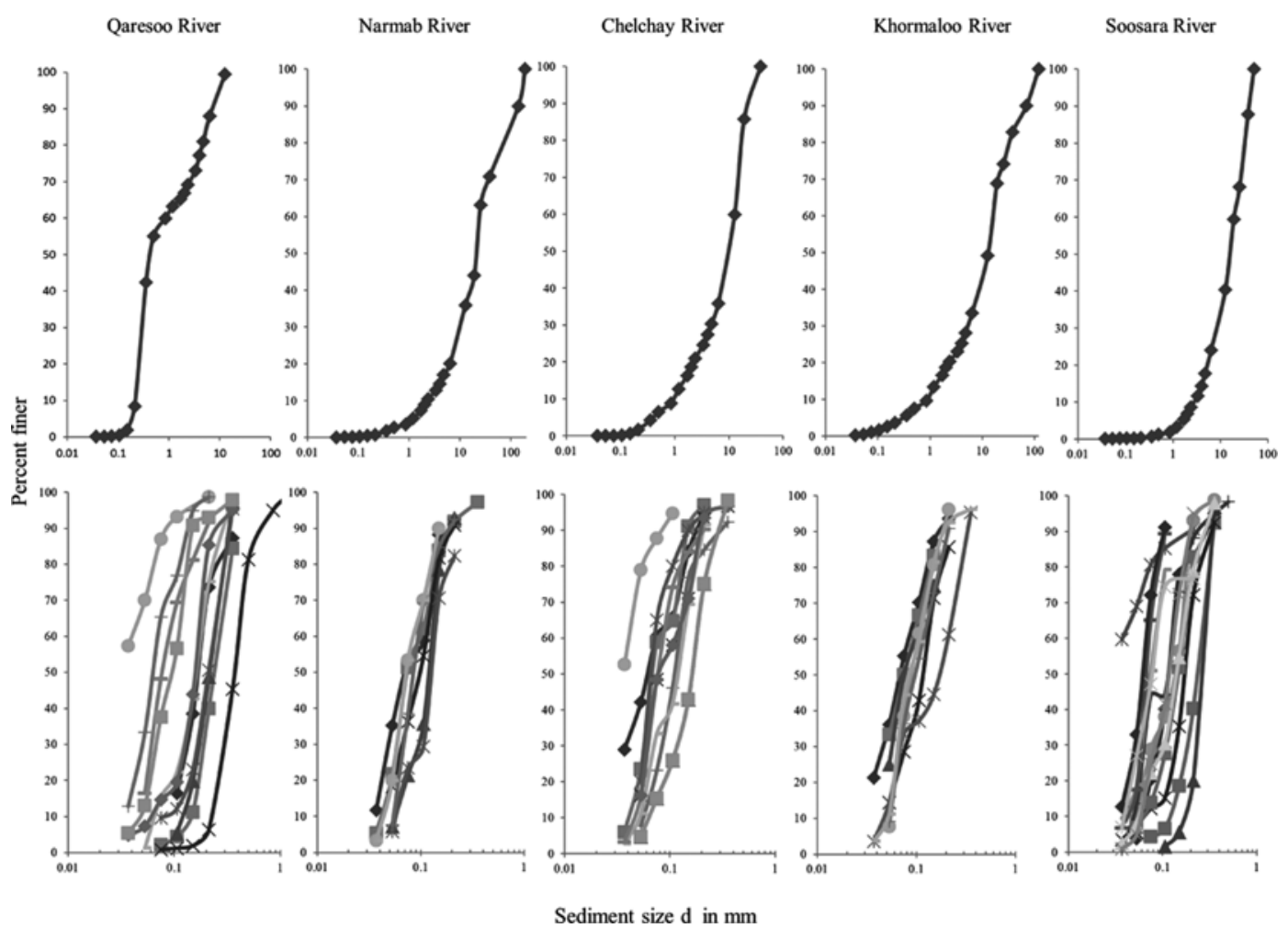

Fig. 4. Grain Size Distribution of: (a) Bed Material and, (b) Suspended Load 
Table 2. Sediment Propoerties of Bed Materials

\begin{tabular}{c|c|c|c|c|c}
\hline Rivers & $\begin{array}{c}\mathrm{d}_{50} \\
(\mathrm{~mm})\end{array}$ & $\begin{array}{c}\mathrm{d}_{\mathrm{a}} \\
(\mathrm{mm})\end{array}$ & $\mathrm{G}$ & $\mathrm{s}_{0}$ & $\begin{array}{c}\mathrm{W}_{\mathrm{s}} \\
\left(\mathrm{ms}^{-1}\right)\end{array}$ \\
\hline Qaresoo & 0.43 & 1.97 & 1.16 & 3.7 & 0.063 \\
\hline Narmab & 22 & 19.2 & 3.8 & 2.7 & 0.66 \\
\hline ChehelChay & 9.8 & 8.3 & 3.9 & 2.2 & 0.44 \\
\hline Khormaloo & 13 & 14 & 5.6 & 2.7 & 0.51 \\
\hline Soosara & 16 & 15.4 & 2.9 & 2.1 & 0.56 \\
\hline
\end{tabular}

Table 3. Sediment Size Properties of Suspended Load

\begin{tabular}{c|c|c|c|c}
\hline River & $\begin{array}{c}\mathrm{d}_{50}(\mathrm{~mm}) \\
\text { Min-Max }\end{array}$ & $\begin{array}{c}\text { Mean Median } \\
\text { diameters } \\
(\mathrm{mm})\end{array}$ & $\begin{array}{c}\mathrm{G} \\
\text { Min-Max }\end{array}$ & $\begin{array}{c}\text { Mean Geometric } \\
\text { standard } \\
\text { deviations }\end{array}$ \\
\hline Qaresoo & $0.06-0.95$ & 0.26 & $1.46-8.56$ & 2.33 \\
\hline Narmab & $0.07-0.12$ & 0.09 & $1.6-1.9$ & 1.74 \\
\hline ChehelChay & $0.04-0.16$ & 0.09 & $1.4-2.7$ & 1.8 \\
\hline Khormaloo & $0.03-0.26$ & 0.13 & $1.1-3$ & 1.7 \\
\hline Soosara & $0.07-0.17$ & 0.1 & $1.6-2.4$ & 2 \\
\hline
\end{tabular}

sampler for wading measurements in natural streams. In this study, depth integrated samples used as input data for both MEP and SEMEP methods to calculate total load.The summation of bed load and suspended load are used as measured total load to compare the applicability of MEP and SEMEP.

In addition to sediment sampling, hydrological data including flow velocity and water depth intervals of one meter distance, cross sectional area, wetted perimeter, width and water temperature were measured in all data sets (see Table 1).

Grain size distribution of sediment samples including bed material and suspended loads (Table 2 and 3 ) were measured via sieve analysis. Suspended load sieve analysis for all data sets and all 5 rivers were carried out seperately, while for bed material sediments an aggregate of samples from 9 different locations (3 samples from right bank, 3 samples from middle and 3 samples from left bank) in one kilometer reach of rivers were collected with a grab sampler.

In MEP Analysis grain size distribution of suspended load and bed material were needed to classify bins (particle size classes) (see Fig. 4), whereas in SEMEP method the total sediment discharge calculation was based on a median grain size in suspension (Table 3, 2nd and 3rd column).

For bed materials the diameter of the $50^{\text {th }}(d 50)$ percentile particle sizes $(\mathrm{mm})$ were extracted from the analysis in addition to particle mean diameter $\left(d_{a}\right)(\mathrm{mm})$, geometric standard deviation $(G)$, sorting coefficient $\left(s_{0}\right)$ and fall velocity (ws) (see Table 2).

For suspended load, minimum, maximum and mean values of particle median diameter, and geometric standard deviation are presented in Table 3.

\subsection{Statistical Analysis}

Four Statistical parameters used to determine the accuracy of SEMEP and MEP methods including Mean discrepancy ratio, Coefficient of determination, Mean absolute percent error and
Table 4. Common Statistical Measures for Evaluating the Results

\begin{tabular}{c|c}
\hline Function Name & Equation \\
\hline $\begin{array}{c}\text { Mean discrepancy } \\
\text { ratio }\end{array}$ & $R_{\text {mean }}=\frac{\sum_{i=1}^{n} \frac{Y_{i}}{X_{i}}}{n}$ \\
\hline $\begin{array}{c}\text { Coefficient of } \\
\text { determination }\end{array}$ & $R^{2}=\left(\frac{\sum_{i=1}^{n}\left(X_{i}-\bar{X}\right)\left(Y_{i}-\bar{Y}\right)}{\sqrt{\sum_{i=1}^{n}\left(X_{i}-\bar{X}\right)^{2} \sum_{i=1}^{n}\left(Y_{i}-\bar{Y}\right)^{2}}}\right)^{2}$ \\
\hline $\begin{array}{c}\text { Mean absolute } \\
\text { percent error }\end{array}$ & $M A P E=\frac{\sum_{i=1}^{n} \frac{a b s\left(X_{i}-Y_{i}\right)}{X_{i}}}{n}$ \\
\hline $\begin{array}{c}\text { Concordance } \\
\text { correlation coefficient }\end{array}$ & $\rho_{c}=\frac{2 S_{X Y}}{S_{X}^{2}+S_{Y}^{2}+(\bar{X}-\bar{Y})^{2}}$ \\
\hline
\end{tabular}

$X_{i}$ is the measured load; $S_{X Y}$ is the covariance; $S_{X}^{2}$ and $S_{Y}^{2}$ are the variances; $Y_{i}$ is the calculated load; $X$ is the average measured load; $Y$ is the average calculated load; $n$ is the number of samples.

Concordance correlation coefficient (Table 4).

\section{Results and Discussion}

Evaluation based on absolute values indicate that the results of the SEMEP method were remarkably greater than those of the MEP method in all gravel bed rivers (Fig. 5). While in the sand bed river (Fig. 6) their differences were smaller.

Consequently, in sand bed rivers both method reach approximately same results, but in gravel bed rivers the results are noticeably different, and more statistical analysis should be made to recognize which method achieve better results. Discrepancy ratio

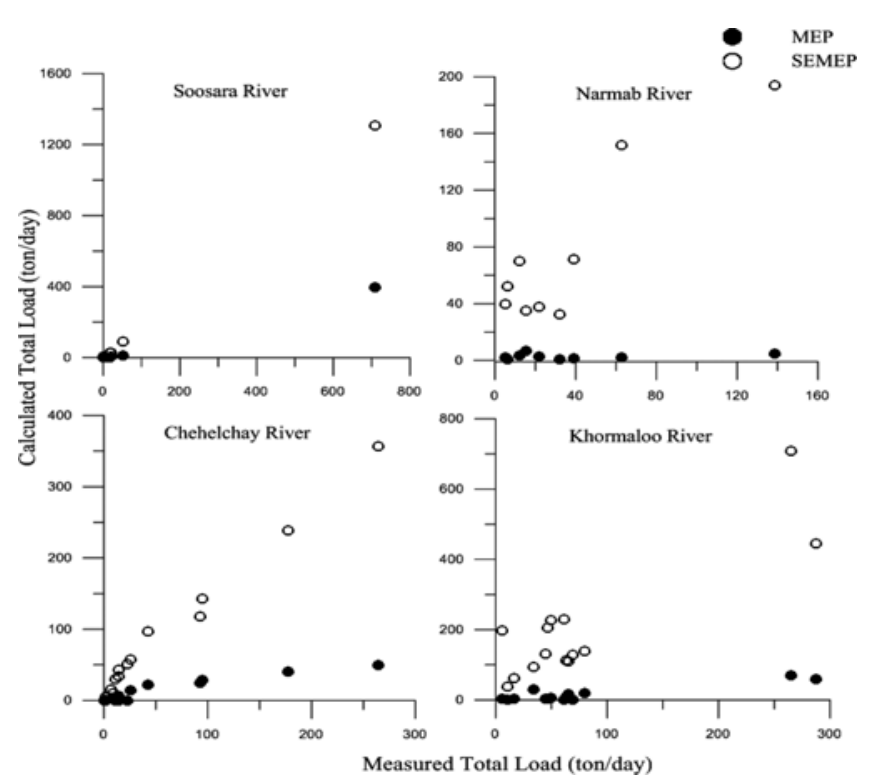

Fig. 5. Comparisons between Calculated (SEMEP and MEP Models) and Measured Total Sediment Load (ton/day) in Gravel Bed Rivers 


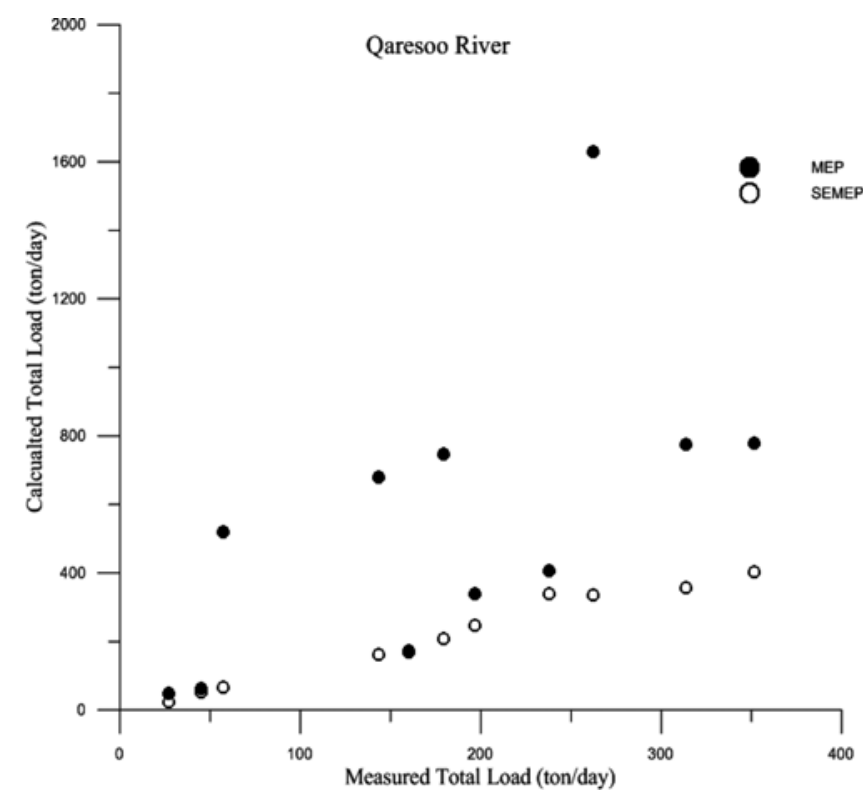

Fig. 6. Comparisons between Calculated (SMEPE and MEP Models) and Measured Total Sediment Load (ton/day) in a Sand Bed River (Qaresoo River)

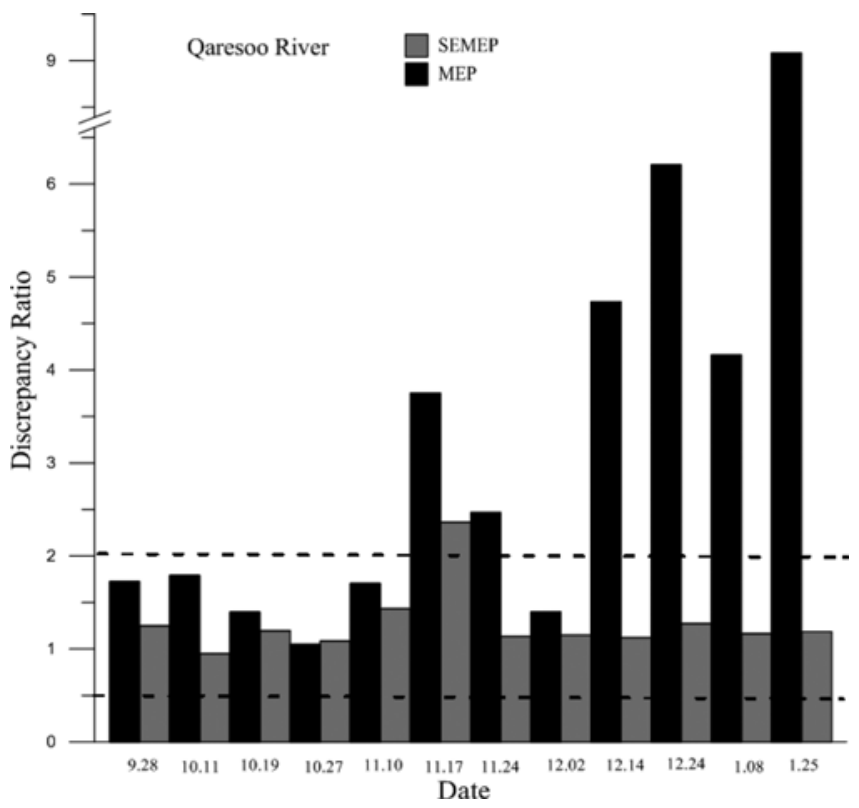

Fig. 7. Discrepancy Ratio of Measurements for Sand Bed River

of all sampling dates for the sand bed river and gravel bed rivers are illustrated in Fig. 7 and Fig. 8, respectively.

The dashed lines show the discrepancy ratio between 0.5 and 2 (factor 2). In the sand bed river, almost all datasets are within the dashed lines using SEMEP method.

The number of data sets that lay between 0.5 to 2 dashed lines is 4, 6, 7, 5 using SEMEP and 0, 2, 1, 1 using MEP for Narmab, Chehelchay, Soosara, Khormaloo Rivers, respectively.. Considering only discrepancy ratio as statistic indices proves that SEMEP can predict total load better than MEP.

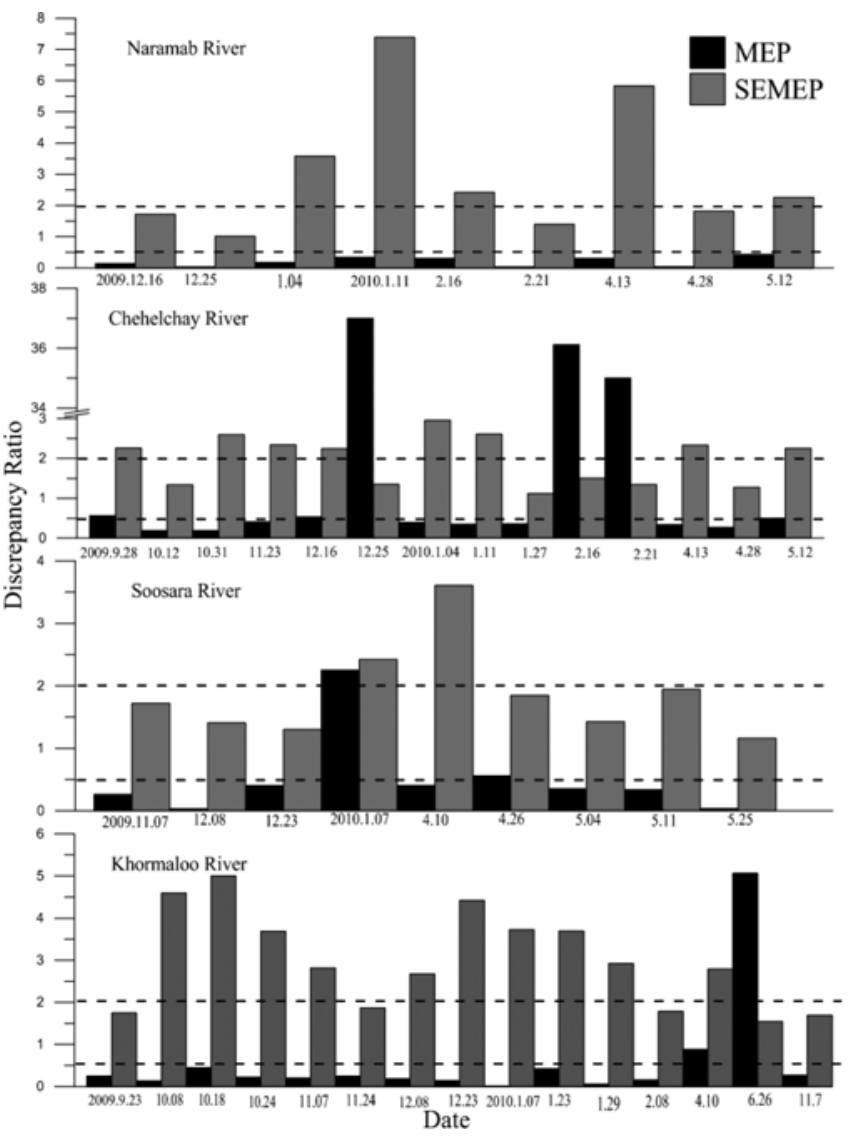

Fig. 8. Discrepancy Ratio of Measurements in Gravel Bed Rivers

\subsection{Evaluation of Modified Einstein Procedure (MEP)}

Table 5 shows the results of statistical analysis for computing total sediment load in all rivers. In Qaresoo River, coefficient of determination was 0.99 , while in Narmab, Chelchay and Khormaloo Rivers, this value was far from unity with $0.45,0.78$ and 0.47 , respectively. The results show that using the MEP method as total sediment load predictor for sand bed river, showed better results compared with gravel bed rivers (except Soosara River). This is due to the fact that MEP originated from Einstein formula, and Einstein formula is mainly based on sand bed rivers.

Among gravel bed rivers, Soosara River could only predict tolerably with MEP method. In this river mean discrepancy ratio was in the range of factor $2(0.5<\mathrm{R}<2)$ and concordance coefficient was closer to unity with 0.73 . The most important characters that make a discriminate between Soosara river and the other three gravel bed rivers was its small size and less water discharge (see Table 1).

\subsection{Evaluation of Series Expansion Modified Einstein Pro- cedure (SEMEP)}

The reults of Shah-Fairbank and Julien (2010) on fourteen rivers in the US indicated that SEMEP performed quite well when the value of $u_{*} / \omega$ was greater than 5 (or Rouse number less 
Table 5. Statistical Results for MEP\& SEMEP

\begin{tabular}{|c|c|c|c|c|c|c|c|c|c|}
\hline Rivers & Bed type & $u_{*} / w$ & $\mathrm{n}$ & Total $n$ & Method & MAPE & $\mathrm{R}^{2}$ & $\rho_{c}$ & $\mathrm{R}_{\text {mean }}$ \\
\hline \multirow{2}{*}{ Qaresoo } & \multirow{2}{*}{ Sand } & $>5$ & 12 & \multirow{2}{*}{12} & MEP & 2.11 & 0.99 & 0.42 & 2.9 \\
\hline & & $<5$ & 0 & & SEMEP & 0.17 & 0.99 & 0.64 & 1.27 \\
\hline \multirow{2}{*}{ Narmab } & \multirow{2}{*}{ Gravel } & $>5$ & 5 & \multirow{2}{*}{9} & MEP & 0.79 & 0.45 & 0.14 & 0.2 \\
\hline & & $<5$ & 4 & & SEMEP & 1.87 & 0.82 & 0.58 & 2.5 \\
\hline \multirow{2}{*}{ Chelchay } & \multirow{2}{*}{ Gravel } & $>5$ & 14 & \multirow{2}{*}{14} & MEP & 6.3 & 0.78 & 0.04 & 9.3 \\
\hline & & $<5$ & 0 & & SEMEP & 0.96 & 0.98 & 0.84 & 1.96 \\
\hline \multirow{2}{*}{ Soosara } & \multirow{2}{*}{ Gravel } & $>5$ & 9 & \multirow{2}{*}{9} & MEP & 0.83 & 0.99 & 0.73 & 0.53 \\
\hline & & $<5$ & 0 & & SEMEP & 0.84 & 0.99 & 0.71 & 1.94 \\
\hline \multirow{2}{*}{ Khormaloo } & \multirow{2}{*}{ Gravel } & $>5$ & 15 & \multirow{2}{*}{15} & MEP & 1.33 & 0.47 & 0.28 & 0.3 \\
\hline & & $<5$ & 0 & & SEMEP & 1.73 & 0.99 & 0.57 & 2.7 \\
\hline
\end{tabular}

than 0.5 ) and performed poor when $u_{*} / w$ was less than 5 . This was in agreement with current results. In Narmab River, 4 out of 9 datasets showed $u_{*} / \omega$ smaller than 5 , while in other gravel bed rivers $u_{*} / \omega$ was greater than 5 , and this is why Narmab showed poor results among gravel bed rivers in SEMEP method. Correlation coefficient in Narmab River was far from one $\left(\mathrm{R}^{2}=\right.$ 0.82 ), while in other gravel bed rivers, this coefficient was close to one (see Table 5).

Among all gravel bed rivers, Soosara River indicated better results using SEMEP method with least mean absolute percent error $(\mathrm{MAPE}=0.84)$ and mean discrepancy ratio within the range of 0.5 to $2\left(\mathrm{R}_{\text {mean }}=1.94\right)$. Looking to Table 1 shows that the Soosara and Narmab Rivers are deeper than the other gravel bed rivers. Similar results were obtained using SEMEP method following Shah-Fairbank (2009) that deeper rivers gave a better estimate of total sediment discharge than shallow rivers.

\subsection{Comparison between SEMEP and MEP Methods}

In a sand-bedded river (Qaresoo River) the results of SEMEP method was remarkably better than MEP method. Statistical parameters can prove it (see Table 5). In SEMEP method, calculated and measured total load are somehow equal (Mean discrepancy ratio was 1.27 ) while MEP model compute total load dicharge approximately 3 times larger than averaged measured values (Mean discrepancy ratio was 2.9). In SEMEP method mean absolute percent error was noticeably closer to zero with 0.17 (compared to MEP with 2.11) and Concordance correlation coefficient was closer to one with 0.64 (compared to MEP with 0.42), consequently using series expansion to solve Einstein integrals $\left(\mathrm{I}_{1}\right.$ and $\mathrm{I}_{2}$ ) (SEMEP method) reach to better results than using trapezoidal method to solve $I_{1}$ and $I_{2}$ parameters (MEP method).

For gravel bed rivers except Soosara river, SEMEP method was better in predicting total load than MEP method. In Narmab, Chelchay and Khormaloo Rivers coefficient of determination was $0.82,0.98$ and 0.99 using SEMEP method and 0.45, 0.78 and 0.47 using MEP method, respectively (see Table 5). Poor results of MEP method in Narmab River show the weakness of this approach to predict total load in very mild slope rivers ( $\mathrm{I}=$ $0.0003 \mathrm{~m} / \mathrm{m}$ in Narmab River).
In Soosara River, coefficient of determination in both methods was equal with 0.99 , but mean absolute percent error and concordance coefficient in MEP method was slightly better than SEMEP. In Total, MEP method in Soosara River tends to overestimate $\left(\mathrm{R}_{\text {mean }}=0.53\right)$ and SEMEP tends to underestimate $\left(\mathrm{R}_{\text {mean }}=1.94\right)$.

\section{Conclusions}

The goal of study is analysing SEMEP method and compare it with MEP method for computing total sediment load, which conducted for one sand bed river and four gravel bed rivers. The results showed that the accuracy of sediment discharge calculations depend on the ratio of the shear velocity $u_{*}$ to the settling velocity $\omega$. The results also showed, in a sand-bedded river (Qaresoo River) SEMEP method was remarkably better than MEP method and for gravel bed Rivers, except Soosara River, SEMEP was better in predicting total load than MEP method. In summary, the SEMEP was a more comprehensive method in computing total sediment load from informations gathered with depth integrated suspended load sampler in both gravel and sand bed rivers.

\section{References}

Albert, J. M. (2004). Hydraulic Analysis and double mass curves of the middle rio grande from cochiti to sa marcial, MSc Thesis, Colorado State University.

Altunkaynak, A. (2010). "Suspended sediment concentration prediction by Geno-Kalman filtering." Expert Systems with Applications, Vol. 37, No. 12 , pp. 8583-8589.

Azamathulla, H. M., Ghani, A. A., and Fei, S. Y. (2012). "ANFIS-Based approach for predicting sediment transport in clean sewer." Applied Soft Computing, Vol. 12, No. 3, pp. 1227-1230.

Azamathulla, H. M., Kiat, C. C., Ghani, A. A., Hasan, Z. A., and Zakaria, N. A. (2009). "An ANFIS-based approach for predicting the bed load for moderately-sized rivers." Journal of HydroEnvironment Research, Vol. 3, No. 1, pp. 35-44.

Blanchard, R. A., Ellison, C. A., Galloway, J. M., and Evans, D. A. (2011). Sediment concentrations, loads, and particle-Size distributions in the Red River of the North and selected tributaries near Fargo, North Dakota, during the 2010 spring high-flow event, U.S. Geological Survey Scientific Investigations Report 2011-5064. 
Garde, R. J. and Ranga Raju, K. G. (2000). Mechanics of sediment transport, New Age International, New Delhi.

Gomez, B. and Church, M. (1989). "An assessment of bed load sediment transport formulae for gravel bed rivers." Water Resources Research, Vol. 25, No. 6, pp. 1161-1186.

Guo, J. and Julien, P. Y. (2004). "An efficient algorithm for computing Einstein integrals." Journal of Hydraulic Engineering, Vol. 130, No. 12, pp. 1198-1201.

Habersack, H. M. and Laronne, J. B. (2002). "Evaluation and improvement of bed load discharge formulas based on Helley-Smith sampling in an alpine gravel bed river." Journal of Hydraulic Engineering, Vol. 128, No. 5, pp. 484-499.

Haddadchi, A., Movahedi, N., Vahidi, E., Omid, M. H., and Dehghani, A. A. (2013b). "Evaluation of suspended load transport rate using transport formulas and artificial neural network models (Case study: Chelchay Catchment)." Journal of Hydrodynamics, Ser. B Vol. 25, No. 3, pp. 459-470.

Haddadchi, A., Omid, M. H., and Dehghani, A. A. (2012). "Assessment of bed-load predictors based on sampling in a gravel bed river." Journal of Hydrodynamics, Ser. B Vol. 24, No. 1, pp. 145-151.

Haddadchi, A., Omid, M. H. and Dehghani, A. A. (2013a). "Bedload Equation Analysis Using Bed Load-Material Grain Size." Journal of Hydrology and Hydromechanics, Vol. 61, No. 3, pp. 241-249.
Haddadchi, A., Omid, M. H., and Sdehghani, A. A. (2013c). "Total load transport in gravel bed and sand bed rivers case study: Chelichay watershed." International Journal of Sediment Research, Vol. 28, No. 1, pp. 46-57.

Julien, P. Y. (2010). Erosion and sedimentation, Cambridge University Press, New York.

Shah-Fairbank, S. C. (2009). Series expansion of the modified einstein method, $\mathrm{PhD}$, Colorado State University.

Shah-Fairbank, S., Julien, P., and Baird, D. (2011). "Total sediment load from SEMEP using depth integrated concentration measurements." Journal of Hydraulic Engineering, Vol. 137, No. 12, pp. 1606-1614.

Shah-Fairbank, S. C., Julien, P. Y., and Guo, J. (2008). Applicability of the modified einstein procedure, Hydrology Days, Colorado State University.

Yang, C. T. (1996). Sediment transport theory and practice, The McGrawHill Companies, Inc., New York.

Yang, C. T., Marsooli, R., and Aalami, M. T. (2009). "Evaluation of total load sediment transport formulas using ANN." International Journal of Sediment Research, Vol. 24, No. 3, pp. 274-286.

Zhu, Y.-M., LU, X. X., and Zhou, Y. (2007). "Suspended sediment flux modeling with artificial neural network: An example of the ongchuanjiang River in the Upper Yangtze Catchment, China." Geomorphology, Vol. 84, Nos. 1-2, pp. 111-125. 